\title{
THEMES, ITERATION, AND RECOVERABILITY IN ACTION RESEARCH
}

\author{
Sue Holwell \\ Open Systems Research Group \\ The Open University
}

\begin{abstract}
This paper develops three concepts important to the practice of action research - recoverability, research themes, and iteration — by highlighting their applicability beyond single action research studies. The concepts are discussed against a program of action research, undertaken by a multidisciplinary research team, with a research focus on local, sector and national levels. This contrasts with the more usual pattern of action research in single situations.

Action research is criticized on the grounds that it lacks generalizability and external validity from one-off studies. Goodness criteria have been derived to address these and other criticisms. The recoverability criterion, less strong than the repeatability of experimentation, is central to these. A second concept, that of research themes, links the recoverability criterion and iteration in action research. Iteration within and between projects and the notion of critical mass, of doing work in more than one setting, address the limitations of single setting studies.
\end{abstract}

Keywords: Action research, research methodology, multidisciplinary research

\section{ACTION RESEARCH IN INFORMATION SYSTEMS}

The advocacy and exhortation of the debates about research methodology in the 1980s have been replaced by discussion about the appropriateness of different modes of research, what constitutes good research within a particular methodological stream, and the practicalities of different modes of research (as examples, see Avison et al. 1999; Baskerville et al. 1997; Baskerville and Wood-Harper 1996).

Action research is a case in point. It is now accepted as a relevant approach for IS research, as evidenced by the publication of IS journal issues dedicated to action 
research (Information, Technology \& People in 2001 and a forthcoming issue of MIS Quarterly).

\subsection{Characteristics of Action Research in IS}

Several varieties of action research are recognized in IS (Baskerville and WoodHarper 1998). Other disciplines, notably health and education, where action research is associated with improvement in professional practice, have a different understanding (Hart et al. 1995).

Nevertheless, action research has some generally accepted characteristics: the researcher is immersed in the situation; the work unfolds in response to the situation and not to the researcher's requirements; the questions, problems, and puzzles are taken from the local context; descriptions and theories are built up by iteration within the context and are tested within the situation and there is close collaboration between researchers and actors, (Argyris et al. 1985; Baskerville and Wood-Harper 1996; Burrell and Morgan 1979; Lincoln and Guba 1985; Robson 1993; Whyte 1991).

Any research may be thought of as entailing three elements: $(F)$ some linked framework of ideas and concepts; (M) a way of applying the ideas, and (A) an area of interest in which to apply them (Checkland and Holwell 1998a). For action research, the addition of the research interests being embodied in a set of themes is necessary (Figure 1).

Here the researcher, interested in particular themes, declares $\mathrm{F}$ and $\mathrm{M}$, then enters a situation in which the themes are relevant and becomes involved as participant and researcher. Work to effect change and improvement follows with the researcher committed to continuous reflection on the collaborative process and its outcomes. This entails trying to make sense of the unfolding experience of A using the declared $\mathrm{F}$ and $\mathrm{M}$. This may involve rethinking of earlier phases, and it is the declared $\mathrm{F}$ and $\mathrm{M}$ that allows this to be done coherently.

In response to criticisms ofinterpretive research, including action research, in terms of the generalizability of the results from (usually) a single situation and the quality with which it is undertaken, goodness criteria have been proposed. These essentially come down to substantiating the approach in the particular case, careful and documented data collection and analysis, iteration, and making all elements explicit at the outset (Baskerville and Wood-Harper 1996; Eden and Huxham 1996; Gummesson 1988; Kock et al. 1997; Lau 1997; Marshall 1990). In particular, iffindings are to be taken seriously, then they must be supported by appropriate arguments and/or evidence, i.e., an adequate warrant against a particular framework (Checkland 1991; Checkland and Holwell 1998a; Phillips 1992).

\section{RECOVERABILITY, THEMES, AND ITERATION}

\subsection{Recoverability}

It is the recoverability criterion, that is the crucial one in action research (Checkland and Holwell 1998a). If we imagine a spectrum of knowledge acquisition from experimental natural science at one end to story telling at the other, then along that spectrum 


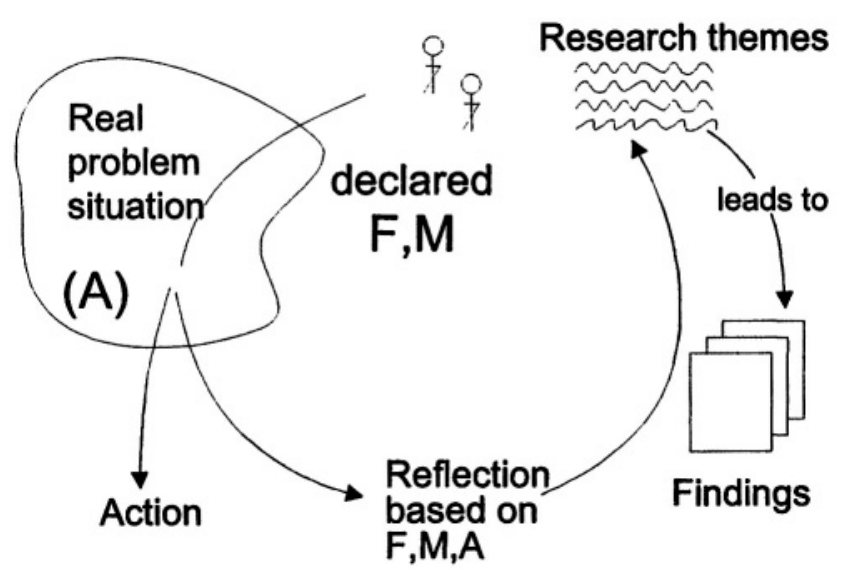

Figure 1. The Cycle of Action Research (Adapted from Checkland and Holwell 1998b)

will be very different criteria forjudging the truth-value of the claims made. Traditional scientific experiments would be at one end and at the other, the weaker criterion that this (research) story is plausible. However, action researchers have to do better than simply settling for plausibility (Checkland and Holwell 1998a).

To do this requires, at the least, that the research process is recoverable by interested outsiders. Therefore, the set of ideas and the process in which they are used methodologically must be stated, because these are the means by which researchers and others make sense of the research. Action researchers should be able to enact a process based on a declared-in-advance methodology that encompasses a particular framework of ideas in such a way that the process is recoverable by anyone interested in subjecting the research to critical scrutiny. This principle is almost totally neglected in the action research literature (Checkland and Holwell 1998b) although some practical difficulties that occur if the framework is not declared in advance are noted (Kock 1997).

The points listed as goodness criteria earlier are subsumed under this concept. The recoverability criterion is the first of three concepts that are important to the practice of action research.

\subsection{Themes}

The second concept, that research interests are embodied in a set of themes, was referred to in the description of action research in Figure 1. The cycle of action research in Figure 1 has researchers with a set of research themes taking action in a situation relevant to those themes, and exploring it via a declared framework and methodology. Findings may be about any or all of the elements F, M, and A and the themes, and new themes may be added (Checkland and Holwell 1998b). The researcher's interests, embodied in themes are not necessarily derived from a specific context. Rather, they are the longer term, broader set of questions, puzzles, and topics that motivate the researcher. Such research interests are rarely confined to one-off situations. 
Given this, and because each new research project is an iteration in a longer term personal research program, then interventions need not be pre-selected (or even negotiated as tightly as Kock, McQueen and Rouse [1996] suggest).

The particular questions, problems, and puzzles through which the themes are explored do come from a particular intervention context. Moreover, research themes are unlikely to be completely resolved through a single intervention, and the linking of projects (both forward and backward) via research themes means that iteration can be thought of differently to iteration within and around the action research cycle.

\subsection{Iteration}

The third concept, iteration, is a recognized, and much discussed, characteristic of action research, particularly as a means of addressing criticisms that findings are, first, not generalizable from one-offinterventions at single sites (the pattern of classical action research in IS) and, second, that action research lacks rigor (Kock et al. 1997).

However, it can be more complex than repetitions of the cycle through the stages (Checkland 1991; Lewin 1951; Susman and Evered 1978) if thought of in relation to a set of themes explored over time through several different organizational contexts.

\section{CONCEPTS IN USE}

\subsection{The Research Program}

The work commenced in the first year as a form of internal market in the UK National Health Service in which purchasers of health services for a local population would contract with providers of health services (general practitioners, hospitals and community units) for the delivery of services(Checkland and Holwell 1998b).

It is a program of action research with the prime research objective of understanding the developing nature of the contracting relationship with a view to defining how it could be improved.

It was concerned with sense making at the level of the whole (the UK National Health Service) while maintaining a focus on several layers of detail (organizational levels). It is complex in execution, including several projects overlapping in time, it covers work from different bodies of knowledge, and was undertaken by a sevenmember multidisciplinary team with different intellectual traditions and the issues explored cross many organizational boundaries.

The work, done over a 4-year period, followed a three-part design and the overall course of the research is depicted in Figure 2, which is chronological from [1] through [16]. Figures in square brackets hereafter refer to items in Figure 2.

The work involved 30 different city and rural NHS sites, with 60 people taking part in Phase One and 3 to 20 people involved in each of the 10 separate action research projects of Phase Two [9a through 9j].

Phase One consisted of extensive interviewing to gather a range of perceptions of the contracting process as it was being initiated and yielded a richer model [5] than the one used to structure the interviews [1]. 


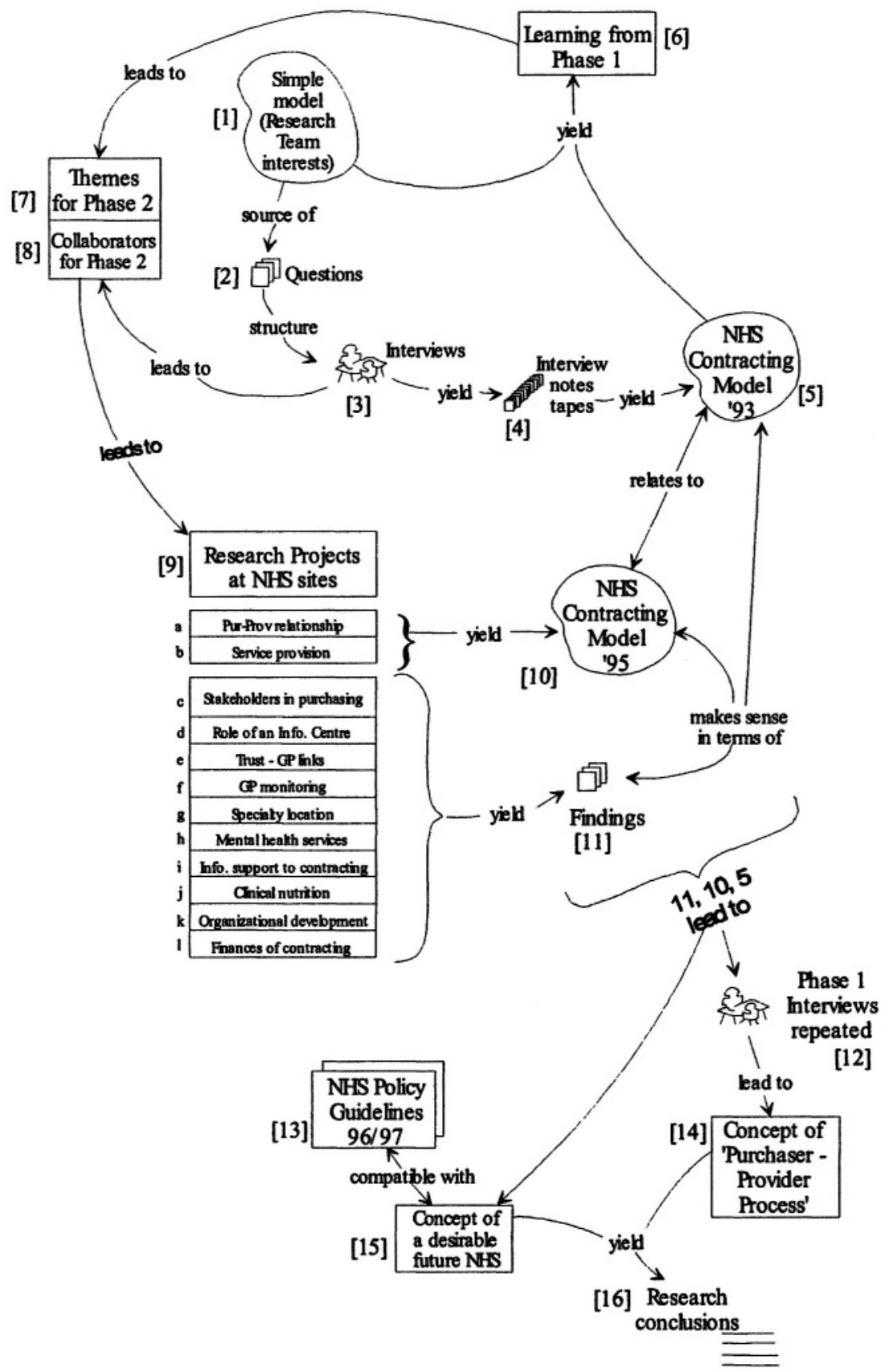

Figure 2. The Overall Arocess of This Research 
Phase Two consisted of 12 separate projects [9] carried out with a number of different NHS organizations. Two of these [9a and 9b] produced a still richer model [10] against which the individual findings from the other 10 studies and model [5] also made sense.

Phase Two research outcomes came from the study of specific findings from the research [9a through 91] and two models, one expressing the aspirations in the NHS at the end of first year [5], the other making sense of the reality two years later [10].

Phase Three consisted of gathering all of the results together to draw general conclusions.

The framework and methodology are declared and both the process and outcomes are clearly linked to them throughout. This addresses three of the four elements suggested for action research in IS (Lau 1997) conceptualization, design, and process.

\subsection{Reflection on the Process}

This work belongs to the strand referred to in social science as emerging action research (Chisholm and Elden 1993; Elden and Chisholm 1993) because it involves multiple levels of organization engaged in the change process and a wide degree of openness in the research process overall (none of the Phase Two projects were known at the beginning). Moreover, because of the number and range of participating organizations it illustrates the concept of critical mass, of doing research in multiple sites, to increase the external validity of action research (Chisholm and Elden 1993).

In doing multidisciplinary research there are difficulties both in observation and in the interpretation of observation, although multidisciplinary perspectives clearly add to the richness of research. There may be less than full conceptual illumination because some team members lack particular intellectual frameworks, and bringing together different intellectual traditions and patterns of work is not always straightforward. Inevitably, there were some arbitrary closures but these were always subject to regular review by the team.

In this work there are instances of single discipline observations on rich data plus a connected multidisciplinary commentary, a middle ground between full theoretical synthesis of all discipline perspectives, and a set of mutually exclusive discipline-based interpretations.

\subsubsection{Recoverability}

Here the argument that a framework and methodology must be declared in advance is clearly evident, and its evolution in substantive terms traceable. This is not only necessary, as argued earlier, but this program of research, multidisciplinary work with a multilevel research focus, in several research settings over a 4-year period, is simply not possible without a cohering framework of ideas and an overarching methodology.

The research process is clear and recoverable (Figure 2) and the thinking is auditable through the evolution of the models from [1] to [5] in Phase One and [10] at the end of Phase Two. All the findings are mappable onto this latter model. The model of a future vision for the NHS [15] from the end of Phase Three is of a different kind than the others but compatible with them. 


\subsubsection{Themes}

The complexity of the research process, combined with the different interests of the multidisciplinary team, made recognition of the significance of research themes relatively easy. No specific interventions were negotiated to explore any particular themes.

Themes can be thought of as a hierarchy. At the top are the themes that motivate researchers to become involved. Then there are themes more relevant to a particular research program. At the third level, there are themes relevant to particular projects, and finally there are some relevant themes within a particular organizational setting. New themes may be recognized at any time.

Themes are the glue in action research. They make sense of a program of research. They give coherence to multiple site, multiple level multidisciplinary research by linking the separate projects and allowing for cross-fertilization between them.

Carrying forward a set of themes makes sense of calls to do several projects on the same topic (Kock et al. 1997) in order to achieve more generalizable outcomes from the evolving set of themes and of undertaking cross-sectional and long-term longitudinal studies.

The similarity in the learning that emerged from separate Phase Two projects is evidence of the thematic linkages within this work (for example, the importance of the changed role for general practitioners).

Finally, taking the concept of themes seriously makes the dilemma of whether to first define your problem and then negotiate settings and collaborators through which to explore it, or whether to find organizations willing to collaborate and then explore their issues (Kock et al. 1996) less of an issue. As long as settings are potentially relevant to research themes, they are appropriate.

\subsubsection{Iteration}

The pattern of iteration is complex, not least because the research focus was concurrently at several organizational levels (individual purchasers and providers, purchasers and providers as groups, and at the level of the NHS nationally).

Iteration around the stages of a cycle of action research is a recognized characteristic that features in descriptions of action research. Argument that added rigor comes from greater emphasis on iteration generally refers to repetitions of the cycle (diagnose, plan, implement, evaluate, and learn [Susman and Evered 1978]).

The iteration here is similar, but more complex, than that generally described. It is easy to see Figure 2 as being one cycle from diagnosis through to reflection. Phase One of the research design mapping onto the diagnosis stage of Susman and Evered's (1978) five stages of action research, Phase Two mapping onto the action stage, and Phase Three as mapping onto the reflection stage. At one level, this is the case.

However, this is to see the research only at one level, whereas it has multiple layers. There are three kinds of iteration within Phase One. First, iteration was necessary to derive the descriptive concept in the model reflecting the researchers' perspectives [1] used to structure the interviews. Then within Phase One there was diagnosis, action in the form of formal and informal feed back that changed the understanding of the NHS interviewees as they were learning what "contracting" might mean, and reflection in the 
creation of the model [5]. This sense-making, practice-improving outcome is recognized in action research in social science disciplines (e.g., health) as being the action.

Each interview can be seen as an intervention in that the team was a conduit for exchanging perceptions as people in the NHS were developing their own understanding. These, then, are examples of developing ideas from a number of small instances that enables development of a more generalizable model. The interviews were interspersed with formal sessions of reflection. At the end of Phase One the process of building the models leading to the generic model [5] was not only iterative but also included diagnosis, some action, and reflection.

The mapping of Phase Two is more complex again. Each of the action projects in Phase Two fully reflects the iteration that is characteristic of action research. However, this was made more complex because several team members were actually participating in more than one project simultaneously, effectively blurring the boundary between the projects. Again, the importance of carrying a set of themes is particularly relevant. Given that the collaborating sites, as purchasers and providers, were also interacting with each other in the course of their daily activity, there was also cross-fertilization of thinking between collaborators from different organizations.

Phase Three can also be seen as a repetition of the full action research cycle. More interviews were conducted, including some at new sites, there was action in the linking of the NHS policy guidelines to the work and the reflection that gave rise to both the concept for the "Future NHS" and the overall conclusions.

\section{CONCLUSION}

Accounts of action research in IS usually describe single focus, single site studies that are concerned with action as the outcome. However, different kinds of action research are found in other disciplines, such as health and education, where the concern is with the improvement of practice. The research program outlined here is an example. Moreover, its three phases covered a 4-year period, 20 organizations, and included 10 discrete, single site, action research interactions.

Three concepts - recoverability, iteration, and themes - found in various forms in IS action research, and generally discussed under goodness criteria have greater significance in multisite, multidisciplinary research programs than has hitherto been described. Recoverability is exemplified through the research process; complex iteration, between and across separate studies, is described; and attention is drawn to the value of conscious reflecting on a hierarchy of themes that motivate researchers both within a study and over time.

\section{REFERENCES}

Argyris, C.; Putnam, R.; and Smith, D. M. Action Science-Concepts, Methods and Skills for Research and Intervention, San Francisco: Jossey-Bass, 1985.

Avison, D.; Lau, F.; Myers, M.; and Nielsen, P. A. "Action Research: Making Academic Research Relevant," Communications of the ACM (42:1) 1999, pp. 94-97.

Baskerville, R.; Myers, M.; Nielsen, P.A.; and Wood-Harper, A. T. "Panel: The Impact of Action Research on Information Systems," in A. S. Lee, J. Liebenau, and J. I. DeGross 
(Eds.), Information Systems Research: Information Systems and Qualitative Research, London: Chapman \& Hall, 1997, p. 69.

Baskerville, R., and Wood-Harper, A. T. "A Critical Perspective on Action Research as a Method for Information Systems Research," Journal of Information Technology (11:2) 1996, pp. 235-246.

Baskerville, R., and Wood-Harper, A. T. "Diversity in Information Systems Action Research Methods," European Journal ofInformation Systems (7) 1998, pp. 90-107.

Burrell, G., and Morgan, G. Sociological Paradigms and Organizational Analysis, Aldershot, England: Gower, 1979.

Checkland, P. B. "From Framework Through Experience to Learning: The Essential Nature of Action Research," in H-E. Nissen, H. K. Klein, and R. A. Hirschheim (Eds.), Information Systems Research: Contemporary Approaches and Emergent Traditions, Amsterdam: North-Holland, 1991, pp. 397-403.

Checkland, P. B., and Holwell, S. E. "Action Research: Its Nature and Validity," Systemic Practice and Action Research (11:1) 1998a, pp. 9-21.

Checkland, P. B., and Holwell, S. E. Information, Systems and Information Systems: Making Sense ofthe Field, Chichester, England: John Wiley \& Sons, 1998b.

Chisholm, R. F., and Elden, M. "Features of Emerging Action Research," Human Relations (46:2) 1993, pp. 275-297.

Eden, C., and Huxham, C. "Action Research for the Study of Organizations," in S. Clegg, C. Hardy, and W. Nord (Eds.), The Handbook ofOrganizational Studies, Beverley Hills, CA: Sage Publications, 1996, pp. 526-542.

Elden, M., and Chisholm, R. F. "Emerging Varieties of Action Research," Human Relations (46:2) 1993, pp. 121-141.

Gummesson, E. Qualitative Methods in Management Research Bickley, Bromley, England: Chartwell-Bratt, 1988.

Hart, E., and Bond, M. Action Research for Health and Social Care: A Guide to Practice, Buckingham, England: Open University Press, 1995.

Kock, N. F. "Myths in Organizational Action Research: Reflections on a Study of ComputerSupported Process Redesign Groups," Organizations \& Society (4:9) 1997, pp. 65-91.

Kock, N. F., McQueen, R. J., and Rouse, A. "Negotiation in Information Systems Action Research," in Proceedings of the First Information Systems Conference of New Zealand, Los Alamitos, CA: IEEE Computer Society Press, 1996, pp. 164-173.

Kock, N. F., McQueen, R. J., and Scott, J. L. "Can Action Research Be Made More Rigorous in a Positivist Sense? The Contribution of an Iterative Approach," Journal of Systems and Information Technology (1:1) 1997, pp. 1-24.

Lau, F. "A Review on the Use of Action Research in Information Systems Studies," in A. S. Lee, J. Liebenau, and J. I. DeGross (Eds.), Information Systems Research: Information Systems and Qualitative Research, London: Chapman \& Hall, 1997, pp. 31-68.

Lewin, K. Field Theory in Social Sciences, New York: Harper, 1951.

Lincoln, Y. S., and Guba, E. G. Naturalistic Inquiry, London: Sage Publications, 1985.

Marshall, C. "Goodness Criteria: Are They Objective or Judgement Calls?," in E. G. Guba (Ed.), The Paradigm Dialog, Newbury Park, CA: Sage Publications, 1990, pp. 188-197.

Phillips, D. C. The Social Scientist's Bestiary: A Guide to Fabled Threats to, andDefenses of. Naturalistic Social Science, Oxford: Pergamon, 1992.

Robson, J. Real World Research: A Resource for Social Scientists and Practitioner Researchers, Oxford: Blackwells, 1993.

Susman, G., and Evered, R. D. "An Assessment of the Scientific Merits of Action Research," Administrative Science Quarterly (23) 1978, pp. 582-603.

Whyte, W. F. Participatory Action Research, Newbury Park, CA: Sage Publications, 1991. 


\begin{abstract}
ABOUT THE AUTHOR
Sue Holwell has been a member of the Open Systems Research Group at the Open University since 2002. She teaches postgraduate and undergraduate courses in information systems and systems thinking. Prior to joining the Open University, Sue lectured at Cranfield University and Lancaster University. She has been an active action researcher for many years, collaborating with Peter Checkland, including on this program of research. She is coauthor, with Checkland, of Information, Systems and Information Systems and has published about action research, soft systems methodology, and information systems. Before joining academia she worked for 20 years in IS/IT in the Australian Public Service. Sue can be reached at s.e.holwell@open.ac.uk.
\end{abstract}

